\title{
When and How Trustworthiness Matters: Knowledge Transfer and the Moderating Effect of Causal Ambiguity
}

Robert J. Jensen

robertjensen@byu.edu

Gabriel Szulanski

Rossella Cappetta

Follow this and additional works at: https://scholarsarchive.byu.edu/facpub

Part of the Business Administration, Management, and Operations Commons

\section{Original Publication Citation}

Szulanski, G., Cappetta, R., Jensen, R.J. 24. When and How Trustworthiness Matters: Knowledge Transfer and the Moderating Effect of Causal Ambiguity. Organization Science 15 (5): 6-613.

\section{BYU ScholarsArchive Citation}

Jensen, Robert J.; Szulanski, Gabriel; and Cappetta, Rossella, "When and How Trustworthiness Matters: Knowledge Transfer and the Moderating Effect of Causal Ambiguity" (2004). Faculty Publications. 1039. https://scholarsarchive.byu.edu/facpub/1039 accepted for inclusion in Faculty Publications by an authorized administrator of BYU ScholarsArchive. For more information, please contact ellen_amatangelo@byu.edu. 


\title{
When and How Trustworthiness Matters: Knowledge Transfer and the Moderating Effect of Causal Ambiguity
}

\author{
Gabriel Szulanski \\ Department of Strategy and Management, INSEAD, Asia Campus, Ayer Rajah Avenue, 138676 Singapore, \\ gabriel.szulanski@insead.edu \\ Rossella Cappetta \\ Institute of Organization and Information Systems, and SDA Bocconi School of Management, Bocconi University, \\ Viale Isonzo, 23, 20135 Milan, Italy, rossella.cappetta@uni-bocconi.it \\ Robert J. Jensen \\ Department of Organizational Leadership and Strategy, Marriott School of Management, Brigham Young University, 772 TNRB, \\ Provo, Utah 84602, rj33@byu.edu
}

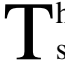
he recognition that better use of existing internal knowledge could enhance survival chances of organizations has spawned substantial interest in the transferability of routinized, experiential learning to additional settings within the organization. Previous research has established that trustworthiness of the source enhances such knowledge transfer. More recent work, however, suggests that this may not always be the case. Yet, little systematic attention has been paid to moderating conditions. The major purpose of this paper is to identify a moderator, causal ambiguity, which delineates the conditions as to when and how a recipient's perception of the trustworthiness of a source affects the effectiveness of the transfer of organizational practices.
\end{abstract}

Key words: knowledge transfer; trust; trustworthiness; causal ambiguity

Better use of existing internal knowledge is seen as essential to the survival and prosperity of organizations. This recognition has spawned substantial interest in the factors that influence the transferability of experiential learning embedded in organizational practices to new settings (Nelson and Winter 1982, Baum and Ingram 1998, Argote 1999, Haleblian and Finkelstein 1999). An important factor in this respect is the perceived trustworthiness ${ }^{1}$ of the source of knowledge.

Indeed, a belief in the value of a trustworthy source is broadly supported by studies of trust and communication in organizations. Well-known experiments in the field of communication have demonstrated that a trustworthy source could substantially affect a recipient's behavior (Hovland et al. 1949, Allen and Stiff 1989, Perry 1996). Likewise, theoretical and empirical studies in the field of trust show how perceptions of trustworthiness increase voluntary deference to authority in organizations (Kramer 1999, pp. 585-586; Tyler and Degoey 1996) and enhance institutionalization of innovations in new settings (Kostova and Roth 2002).

Yet, despite its generally beneficial role, perceived trustworthiness may also promote behaviors that weaken the overall effectiveness of knowledge transfer efforts. Recent studies confine the role of trust in relationships to specific activities and, under certain conditions, encourage actors to complement high levels of trust with correspondingly high levels of distrust (e.g., Sitkin and Roth 1993, Lewicki et al. 1998) or at least with increased monitoring (Langfred 2004). Such cautionary notes resonate with existing findings by communication researchers who have found that a trustworthy ${ }^{2}$ source could distract the recipient from the actual contents of the message thus undermining the effectiveness of communication (Allen and Stiff 1989). In addition, observation by trust researchers has found that trustworthiness could inhibit monitoring by the recipient, thereby decreasing attentiveness and reducing the variety of thought and action (Webb 1996, p. 292).

However, little systematic attention has been paid to the conditions that determine when and how perceived trustworthiness will be related to the effectiveness of knowledge transfer. Evolutionary economics (Nelson and Winter 1982) and the knowledge-based view of the firm (Zander and Kogut 1995) posit that attributes of the knowledge being transferred are primary determinants of the effectiveness of knowledge transfer. As such, they may also moderate when and how trustworthiness affects the effectiveness of knowledge transfer. This paper explores the moderating effect of one specific knowledge attribute, causal ambiguity, on the relationship between trustworthiness and the effectiveness of intrafirm transfers of organizational practices. 


\section{Conceptual Background}

\section{Replication of Routines and the Advice of the Source}

Knowledge transfer is often undertaken to reproduce superior results observed elsewhere within the organization. ${ }^{3}$ Following Nelson and Winter (1982), we use the term "template" or "template site" to refer to the original site where exemplar results are being obtained. An important contribution of evolutionary economics to the understanding of knowledge transfer is to highlight the fact that the template could be causally ambiguous because routines may not be comprehended fully by any of the individuals involved.

There are three possible ways for a recipient ${ }^{4}$ to approach the reproduction of superior results under such circumstances. At a minimum, knowledge of superior results can be used merely to set or adjust expectations for future performance. In addition, a recipient can study the actual practices that underlie those results. However, both of these approaches are likely to involve redundant and possibly costly rediscovery of information that already exists. As a result, when feasible, the recipient can plausibly be expected to first seek the advice of the source when undertaking a transfer. ${ }^{5}$

\section{Causal Ambiguity and the Validity of the Advice of the Source}

The advice of the source is a symbolic expression of the essential drivers of the template's performance, their value, and their context dependence. These aspects of the template are referred to collectively as the template's "Arrow core" (Winter and Szulanski 2001). The advice of the source, when valid, can enhance the effectiveness of the transfer by reducing or eliminating the need for costly efforts to rediscover information that exists already, i.e., to rediscover the Arrow core.

The validity of the contribution of the source, however, is limited by the degree of irreducible uncertainty about the functioning of the template, i.e., by the degree of causal ambiguity (Lippman and Rumelt 1982). The existence of causal ambiguity means that the factors explaining the template's performance cannot be precisely determined (not even ex-post), and that it is therefore impossible to produce an unambiguous conception of how the template works, i.e., to produce a unique list of its key components and of how they interact (see also King and Zeithaml 2001). Some features of causally ambiguous templates are tacit, and thus unlikely to be codified. Others may be quite apparent but may contribute to results in nonobvious ways.

Thus, even though the source is able to achieve superior results, causal ambiguity might limit the depth of understanding of the source, because under such circumstances there is often a gap between formal description or nominal standards-e.g., as represented in training programs and manuals-and actual routine work practices as performed by the organization's members (Brown and Duguid 1991, p. 41; Nelson and Winter 1982, p. 108). Such gaps stem from partial articulation of the espoused rules that govern behavior (Argyris and Schon 1978). Partial articulation results from the partly tacit nature of individual skills (Polanyi 1962), from the partly tacit coordination principles that govern collective action (Kogut and Zander 1992, Winter 1987), from partial knowledge of the production process (Bohn 1994), from the opacity of the organization (Williamson 1975), and from the need for compromise to avoid continuous conflicts (Nelson and Winter 1982). Increasing levels of causal ambiguity are likely to be associated with a wider gap between the espoused description and the actual functioning of the template, thus effectively placing an upper bound on the depth of the source's understanding of its functioning.

\section{The General Effect of Trustworthiness on Knowledge Transfer}

If the source has complete knowledge on how to obtain superior results (i.e., can fully articulate the true Arrow core), then the problem of transfer becomes the problem of accurately communicating the Arrow core. The underlying logic for this statement reflects that of the mathematical theory of communication (Attewell 1992, Shannon and Weaver 1949). This theory treats communication as an act of signaling where a source transmits a fully codified message that is absorbed and then acted on by a recipient. The communication act is designed by the source to influence the behavior of the recipient in a specific way. Accordingly, the transfer is seen to be effective to the extent that it changes the behavior of the recipient in productive ways (Shannon and Weaver 1949). A trusting recipient is more likely to accept the advice of the source and change its behavior, and trust is more likely to occur when the source is perceived as trustworthy (Andrews and Delahaye 2000, Mayer et al. 1995).

Thus, the perceived trustworthiness of the source will significantly influence the likelihood of behavioral change by the recipient. Trust scholars argue that trust increases the amount of information that can be exchanged (Carley 1991, Tsai and Ghoshal 1998), decreases the cost of exchange (Curall and Judge 1995, Zaheer et al. 1998), and increases cooperation with the source of the knowledge (Dirks and Ferrin 2001, Kramer 1999, Tyler and Degoey 1996). Communication scholars (Hovland et al. 1949) argue that when the recipient perceives the source as credible or trustworthy, it will be less suspicious and thus more open and receptive to the message. In sum, a trusting recipient is more likely to comply with the prescriptions of the Arrow core, which is, by assumption, optimal and unambiguous. Increased compliance will be reflected in a more complete and accurate copy of the practices found in the template. This leads to the first hypothesis. 
HYPOTHESIS 1. The perception of a source's trustworthiness will be positively related to the accuracy of the reproduction of the template.

\section{The Moderating Effect of Causal Ambiguity}

When the functioning of the template cannot be completely observed, i.e., it is causally ambiguous, multiple conflicting versions of the Arrow core may coexist. That is because available evidence is not sufficient to select one and rule out the others. Each one of these different perceptions of the Arrow core is likely to be either a distorted and/or simplified version of the "true" one. Distortion may reflect the persistence of rationalized institutional myths (Meyer and Rowan 1977); fragmentary, myopic, and disparate understandings of how the work is accomplished (Carroll 1998); superstitious learning (Levitt and March 1988); and/or faulty memory (Golden 1992). Moreover, as Miller (1993) argues, processes of successful organizations tend, over time, to come to focus more narrowly on a single theme, activity, or issue at the expense of all others, thus becoming more pure or "simple" over time. Therefore, despite best efforts to the contrary, a trustworthy source may still end up supplying a somewhat distorted or simplified account of the true Arrow core of a causally ambiguous template, possibly leaving out crucial details.

When the source cannot have complete knowledge of how to obtain superior results (i.e., does not know and cannot fully articulate the true Arrow core), then the problem of transfer becomes a problem of replication (i.e., an iterative process consisting of a set of attempts to reproduce the results using as a referent the information available at the template site to correct implementation deficiencies) (Winter and Szulanski 2001). March et al. (1991) argue that a prerequisite for social action is the existence of reliable, i.e., stable and shared, conceptions of work practices. Given that organizations tend to converge on increasingly simplistic conceptions of the Arrow core (Miller 1993) and given the difficulty of changing prevailing shared conceptions (March et al. 1991, Nelson and Winter 1982), it is reasonable to expect that when consulted a source will likely provide a hypothetical Arrow core that reflects prevailing shared understandings and beliefs. As argued earlier, the higher the level of causal ambiguity, the greater the potential gap between prevailing shared beliefs and the actual work practices, thus limiting the value of the source's advice. Under these circumstances, knowledge of the source's Arrow core may not be sufficient to attain desired results.

For this reason, the recipient will need to supplement, at some point during the transfer, the advice of the source with inferences drawn from direct observation of the template. Because such action may require substantial additional effort, the lower the initial level of success experienced when acting solely based on the advice of the source, the sooner the effort to learn through direct observation begins. Because the value of the advice from the source decreases with causal ambiguity, the higher the level of causal ambiguity, the earlier the recipient could be expected to begin direct observation.

As the recipient begins to observe the template practices directly, these practices (rather than the source's advice) will become the point of reference for problem solving in further iterations. In such situations, as Winter and Szulanski (2001) argue, it is desirable to reproduce the template's practices as accurately as possible to maximize the value of the template site as a referent for problem solving. Otherwise, they explain, "modifications introduced to adapt the established template may create new problems; problems that will have to be solved in-situ through a costly process of trial and error, since they cannot be solved through reference to the established template" (p. 737). Thus, accurate reproduction of the specific details of the original template shortens the time and effort required to pinpoint and correct differences that may exist between the replica and the original. Intel's "copy exactly" philosophy for building semiconductor plants provides a tangible example of the practical meaning of such logic (Iansiti 1998), as do Rank Xerox's policy of forcing country subsidiaries to follow best practice "down to the last detail" until they achieve similar performance (Financial Times 1997) and Great Harvest's learning covenant that holds new franchisees to the "tiniest letter" of their promises to follow the original system (Great Harvest Bread Co. 1999). Thus, in an effective iteration process, the recipient's practices could be plausibly expected to accurately resemble those of the template's site.

However, the recipient will cling to the source's advice longer, i.e., may postpone efforts to learn from direct observation, the more trustworthy the source of advice is perceived to be. Even though the extent of irreducible uncertainty may increase the vigilance of the recipient and motivate it to supplement the advice of the source with direct observation, trustworthiness may act in the opposite direction by inhibiting the felt need for such action (Lewicki et al. 1998), distracting the recipient from the relevant details, reducing the level of attention to detail, operating as a simplifying heuristic in the interpretation of information, which ultimately effectively limits cognitive effort to obtaining a general impression of the source's advice (Allen and Stiff 1989, Perry 1996, Uzzi 1997). Trustworthiness also lowers the incentive of the recipient to reduce uncertainty by monitoring ${ }^{6}$ (Barber 1983, Langfred 2004, Lewis and Weigert 1985, McAllister 1995, Webb 1996), encourages actors to suspend judgment of others (McEvily et al. 2003), and inhibits a critical attitude and critical thinking that is necessary to recognize the limitations of the source's advice (Petty and Cacioppo 1996). Trust scholars argue that the level of comfort with a limited cognitive effort and a less critical attitude is inversely related 
to the concern that damage may result from the interaction with the source (Noteboom 1997).

In sum, trustworthiness could effectively stifle direct observation, thus prolonging the period of time during which the recipient acts solely on the basis of the source's flawed and incomplete Arrow core. ${ }^{7}$ Because once the transfer begins there is a finite window of opportunity during which changes are feasible (Tyre and Orlikowski 1994), the longer the delay in initiating direct observation, the lower the likelihood that direct observation (if it at all occurs) will have substantial impact on the recipient's actions. Hence, one would expect that the relationship between perceived trustworthiness and accuracy will substantially change with increasing levels of causal ambiguity.

Hypothesis 2. As causal ambiguity increases, the positive relationship between the perception of a source's trustworthiness and the level of accuracy of the reproduction of the template will first weaken and then, under conditions of high causal ambiguity, turn negative.

\section{Method}

\section{Sample and Procedures}

The transfer of best practices (O'Dell et al. 1998) provides a propitious setting to observe intrafirm knowledge transfer. Data were collected through a two-step questionnaire survey. The first step of the survey asked companies to provide a list of transfers for study that included sufficient detail about the parties involved in those transfers (i.e., respondents). To provide practices for study, companies were directed to search for transfers of practices that could not be performed by a single individual, but rather required the involvement of a group. More than 60 companies, with varying degrees of experience in the transfer of practices, expressed interest. Of that group, 12 were able to provide such a list, with 8 providing entries of sufficient quality to warrant continuation of their involvement in the research. The eight companies were: AMP, AT\&T Paradyne, British Petroleum, Burmah Castrol, Chevron Corporation, EDS, Kaiser Permanente, and Rank Xerox. Detailed specification regarding the identification and the selection of the companies is included in Appendix 1.

The second step of the survey was devised to analyze specific transfers. The final sample consisted of 271 returned questionnaires, spanning 122 transfers of 38 practices, ${ }^{8}$ for a response rate of $61 \% .{ }^{9}$ The transfer is the unit of analysis. To triangulate and obtain the most objective measures possible, separate but identical questionnaires were sent to an individual within a source, a recipient, and a third-party unit for each transfer. Sources and recipients were subunits of an organization. Third parties were defined as a party knowledgeable with the transfer but not a part of the source or the recipient unit; i.e., a corporate office, an outside consultant, etc. The respondents in each case are individuals representing their organizational unit.

Triangulation using all three respondent types was considered appropriate. It is difficult to assess the perceptions of "units" because the perceptions of individual respondents within a particular unit are likely to be only somewhat representative of their unit's overall perception. Moreover, the perceptions of various units are likely to significantly overlap because perceptions are often developed from depersonalized presumptive rationales based on lessons from prior history, affiliation with specific social categories, formal roles, and organizational rules regarding transaction norms (Kramer 1999). Given sampling restrictions and to obtain the most complete and unbiased data possible, we considered it more appropriate to triangulate by obtaining responses from three different perspectives rather than several from a single perspective. Empirical verification for this approach is found in an intraclass correlation analysis that indicates high inter-rater reliability (from 0.47 to 0.60 for the main variables) between the three perspectives and suggests that observations should consist of the average of the three perspectives for each transfer (average of raters coefficient ranges from 0.73 to 0.82 for the main variables).

The respondents included 110 sources units, 101 recipient units, and 60 third parties. Average item nonresponse was lower than 5\%. An average of 2.2 questionnaires were received for each transfer.

\section{Construction of Measures}

Multiple-item scales were developed for all constructs to ensure the reliability and validity of the measurement system. Little empirical precedent was available to guide the development of the measures (see Zander and Kogut 1995 for an exception). A broad and thorough literature review informed the generation of the initial constructs and the a priori assignment of items to measure those constructs. In-depth clinical work, consultation with subject experts and feedback obtained when piloting the questionnaire helped refine the choice of constructs, identify the most relevant items for those constructs, and select their proper wording given the empirical context. Some items were discarded, but not re-assigned, after the full data set was obtained; the a priori assignment of items was preserved for all constructs, except accuracy, which we introduced ex-post.

Unless otherwise stated, a balanced five-point, Likerttype scale was used to measure most items in the questionnaire: $\mathrm{Y} !=$ "Yes!"; $\mathrm{y}=$ "yes, but"; $\mathrm{o}=$ "no opinion"; $\mathrm{n}=$ "no, not really"; N! = "No!" Following Nunnally's (1978) recommendation, construct scores were computed by adding up the standardized item scores. 
Below we detail the operationalization of the central constructs for this paper. All other constructs are detailed in Appendix 2. Those that are reverse scored are indicated with an (RS).

Causal Ambiguity. The construction of the measure of causal ambiguity was primarily based on the theory of uncertain imitability (Lippman et al. 1982). Five of the eight items in the measure of causal ambiguity are derived from Lippman and Rumelt (1982). The full text of those questionnaire items is: "The limits of the [practice] are fully specified (RS)"; "With the [practice], we know why a given action results in a given outcome (RS)"; "When a problem surfaced with the [practice], the precise reasons for failure could not be articulated even after the event"; "There is a precise list of the skills, resources, and prerequisites necessary for successfully performing the [practice] (RS)"; and "It is well known how the components of that list interact to produce the [practice's] output (RS)."

The remaining three items are designed to infer causal ambiguity from the degree of tacitness of the practice (Winter 1987, Zander and Kogut 1995). The full text of these items is: "Operating procedures for the [practice] are available (RS)"; "Useful manuals for the [practice] are available (RS)"; "Existing work manuals and operating procedures precisely describe what people working in the [practice] actually do (RS)."

Trustworthiness. This scale was designed to assess the perceived trustworthiness of an organizational unit. The choice of specific items was primarily influenced by Walton's (1975) study of the determinants of perceived trustworthiness of organizational subunits and overlap with the Mayer et al. (1995) conception of trustworthiness. To bridge levels of analysis we relied on Nelson and Winter's (1982, p. 98) notion of agent or organizational member, which while typically referring to an individual, applies to any organizational unit that can "accomplish something on its own."

Mayer et al. (1995) propose three attributes of trustworthiness: benevolence, integrity, and ability. In the context of unit-level knowledge transfer, however, ability $^{10}$ is the attribute of greatest consequence. The ability of the source to both achieve results and actually transfer the practice is at the heart of both the efficacy of the transfer and also of perceptions of source unit trustworthiness. While benevolence is not without influence at this level of analysis, it likely plays a different role than at the individual level. In individual-level analyses of trustworthiness, benevolence is usually interpreted as the intention to do no harm. In the context of unit-level transfer, one would not expect a source unit to put forth the costly effort necessary to harm a recipient through transferring false practices. A lack of benevolence at this level of analysis is most likely to result in a lack of motivation, and hence effort, to aid the recipient in the transfer effort. Benevolence, then, at the unit level of analysis and in the context of knowledge transfer, is substantively equal to the source's motivation in the transfer.

Because ability is the central trustworthiness construct of interest and the one most likely to interact with causal ambiguity (what does it mean for the intentions of a source to be causally ambiguous?), we have chosen to focus on ability as the primary measure of trustworthiness. However, because benevolence, in terms of source motivation, is also likely to influence the general efficacy of the transfer, we include a measure of source motivation as a control variable.

Focusing on trustworthiness in terms of source ability, we derived four items from the sources mentioned above. We asked whether superior results of the source were visible and remained stable, whether the source possessed the necessary resources to support the transfer, and whether the source was able to accommodate the needs of the recipient into the practice.

Accuracy. The effectiveness of the transfer is operationalized by how accurately the recipient reproduces a replica of the template. Accuracy has remained a relevant and central construct for those branches of the communication field that focus primarily on directional exchange, as is the case when routines or best practices are transferred within organizations. Not all transfers of knowledge, however, are intended to be accurate. A measure of accuracy must be sensitive to differences between the features of the replica and those of the original template (Muchinsky 1977, Roberts and O'Reilly 1974, Shannon and Weaver 1949), both to intended and unintended modifications introduced to the original template (Eisenberg and Phillips 1991, Stohl and Redding 1987). Communication scholars suggest two types of modifications. Modifications can be general, i.e., affecting the comprehensive meaning of the practice. Alternatively, specific aspects of the practice can be altered while preserving its overall meaning. ${ }^{11}$

The measure of accuracy has eight items. We used six items to assess the level of general modifications. We first asked whether compared to the source's practice, the recipient's one is: $1=$ "Exactly the same"; $2=$ "Essentially the same"; 3 = "Slightly modified"; 4 = "Markedly modified"; 5 = "Completely different" (RS). Then we asked whether modifications were introduced to make the practice workable (RS) and to adapt the practice to different environments (RS). We asked whether unnecessary modifications were performed (RS), whether the practice was modified in ways contrary to expert's advice (RS), and/or whether in altering the practice further problems were created (RS).

Then, we tried to assess specific modifications. We evaluated the incompleteness of the replication by asking whether: 1 = "All modules have been transferred"; 
$2=$ "Only selected, but all the essential modules have been transferred"; $3=$ "Only the essential modules have been transferred"; $4=$ "Only selected modules, some essential some not, have been transferred"; $5=$ "None of the modules have been transferred" (RS). Next, we asked whether original modules of the practice were replaced by existing ones at the recipient's side (RS).

Control Variables. To complete the specification of the model, additional measures are introduced to control for unobserved heterogeneity. These factors include the remaining elements of Shannon and Weaver's (1949) model of communication, i.e., the source's and recipient's motivations, the recipient's absorptive and retentive ability, the proveness of the knowledge transferred, and the elements of the social context (i.e., the ease of the relationship and the fertility of the context). Detailed specification of these items and their expected relationship with accuracy is included in Appendix 2. Second, we added dummy variables to control for the possibility that results are due to firm-specific effects. Finally, we include Kogut and Singh's (1988) measure of cultural distance to control for the appropriateness of the transfer. In some cases modifications to the template may be introduced in response to differences in the recipient's environment, rendering an accurate reproduction less appropriate. It has been argued that such adaptations will be more likely to occur when the distance between the source and recipient environments is greater, making cultural distance an adequate measure of appropriateness (Bartlett and Ghoshal 1989, Prahalad and Doz 1987).

\section{Performance of the Measures}

Table 1 summarizes the performance of the measures, including the dependent variables, the predictors, and the control variables.

Convergent validity (reliability and unidimensionality) was evaluated separately for each construct (Gerbing and Anderson 1988). Cronbach's alpha was used as a measure of reliability because it provides a lower bound to the reliability of a scale and is the most widely used measure (Nunnally 1978). All but one scale had an alpha greater than 0.70 , thus providing an adequate level of reliability for predictor tests and hypothesized measures of a construct (Nunnally 1978, pp. 245-246). The least reliable scale scored only marginally below that standard (0.68). Unidimensionality was assessed through factor analysis and computation of the theta coefficient (Armor 1974, Carmines and Zeller 1979, Zeller and Carmines 1980). The unidimensionality of all 10 scales was adequate. Multicollinearity was checked via tolerance values with a range from 0.395 to 0.873 and an average of 0.698. Finally, all variables meet reasonable assumptions of normality (see Table 1 for skewness and kurtosis values).

Discriminant validity was evaluated for all construct pairs by examining the observed correlation matrix of the constructs. If the correlation between constructs $i$ and $j$ is 1 (i.e., if constructs $i$ and $j$ are perfectly correlated), the observed correlation should be $\left(\alpha_{i}^{0.5}\right) *\left(\alpha_{j}^{0.5}\right)$ where $\alpha_{i}$ and $\alpha_{j}$ are the reliability coefficients for the constructs. In practical terms, testing for discriminant validity entails computing the upper limit for the

Table 1 Performance of Measures

\begin{tabular}{|c|c|c|c|c|c|c|c|c|}
\hline \multicolumn{2}{|c|}{ Construct } & \multirow[t]{2}{*}{ Description } & \multirow{2}{*}{$\frac{\text { Cronbach } \alpha}{0.93}$} & \multirow{2}{*}{$\begin{array}{c}\text { Items } \\
13\end{array}$} & \multirow{2}{*}{$\begin{array}{c}\text { Valid } N \\
140\end{array}$} & \multirow{2}{*}{$\begin{array}{c}\text { Avg. inter } \\
\text { item corr. } \\
0.5\end{array}$} & \multirow{2}{*}{$\begin{array}{c}\text { Skewness } \\
-0.14\end{array}$} & \multirow{2}{*}{$\begin{array}{c}\text { Kurtosis } \\
-0.68\end{array}$} \\
\hline (1) & Source's motivation* & & & & & & & \\
\hline (2) & Trustworthiness & $\begin{array}{l}\text { Degree to which the source of the } \\
\text { best practice is perceived as } \\
\text { trustworthy in terms of ability }\end{array}$ & 0.73 & 4 & 136 & 0.42 & -0.58 & -0.11 \\
\hline (3) & Context & $\begin{array}{l}\text { Degree to which the organizational } \\
\text { context supports the development } \\
\text { of transfers }\end{array}$ & 0.79 & 14 & 140 & 0.23 & -0.04 & 0.65 \\
\hline (4) & Causal ambiguity & Depth of knowledge & 0.90 & 8 & 133 & 0.54 & 0.39 & -0.35 \\
\hline (5) & Knowledge proveness & $\begin{array}{l}\text { Degree of conjecture on the utility of } \\
\text { the transferred knowledge }\end{array}$ & 0.68 & 3 & 138 & 0.42 & -0.57 & 0.14 \\
\hline (6) & Recipient's motivation* & $\begin{array}{l}\text { Motivation of the recipient unit to } \\
\text { support the transfer }\end{array}$ & 0.93 & 14 & 140 & 0.48 & -0.31 & -0.76 \\
\hline (7) & $\begin{array}{l}\text { Recipient's absorptive } \\
\text { capacity }\end{array}$ & $\begin{array}{l}\text { Ability of the recipient unit to identify, } \\
\text { value, and apply new knowledge }\end{array}$ & 0.81 & 9 & 140 & 0.33 & -0.35 & 0.19 \\
\hline (8) & $\begin{array}{l}\text { Recipient's retentive } \\
\text { capacity }\end{array}$ & $\begin{array}{l}\text { Ability of the recipient unit to support } \\
\text { and routinize the use of new } \\
\text { knowledge }\end{array}$ & 0.82 & 6 & 140 & 0.44 & -0.35 & 0.14 \\
\hline & Relationship & $\begin{array}{l}\text { Ease of communication and intimacy } \\
\text { of the relationship }\end{array}$ & 0.70 & 3 & 133 & 0.44 & 0.37 & 0.83 \\
\hline (10) & Accuracy & $\begin{array}{l}\text { Degree of similarity between the } \\
\text { replica and the template }\end{array}$ & 0.79 & 8 & 127 & 0.33 & -0.22 & -0.55 \\
\hline
\end{tabular}

\footnotetext{
*These scales are composed of binary items. Both scales qualify marginally as Guttman scales.
} 
Table 2 Correlations Between the Independent Variables, the Dependent Variables, and the Control Variables (Casewise)

\begin{tabular}{|c|c|c|c|c|c|c|c|c|c|c|c|c|}
\hline & 1 & 2 & 3 & 4 & 5 & 6 & 7 & 8 & 9 & 10 & 11 & 12 \\
\hline (1) Cultural distance & 1.00 & & & & & & & & & & & \\
\hline (2) Source's motivation & $-0.33^{*}$ & 1.00 & & & & & & & & & & \\
\hline (3) Trustworthiness & -0.13 & $0.43^{*}$ & 1.00 & & & & & & & & & \\
\hline $\begin{array}{l}\text { (4) Interaction causal } \\
\text { ambiguity/trustworthiness }\end{array}$ & 0.11 & -0.02 & $0.31^{*}$ & 1.00 & & & & & & & & \\
\hline (5) Context & -0.03 & 0.17 & 0.15 & -0.15 & 1.00 & & & & & & & \\
\hline (6) Causal ambiguity & 0.16 & $-0.39^{*}$ & $-0.53^{*}$ & $-0.26^{*}$ & $-0.36^{*}$ & 1.00 & & & & & & \\
\hline (7) Unproven knowledge & $-0.23^{*}$ & $0.32^{*}$ & $0.38^{*}$ & 0.03 & $0.31^{*}$ & $-0.51^{*}$ & 1.00 & & & & & \\
\hline (8) Recipient's motivation & $-0.29^{*}$ & $0.67^{*}$ & $0.26^{*}$ & 0.11 & $0.19 *$ & $-0.37^{*}$ & $0.20 *$ & 1.00 & & & & \\
\hline $\begin{array}{l}\text { (9) Recipient's absorptive } \\
\text { capacity }\end{array}$ & -0.03 & 0.04 & $0.25^{*}$ & 0.04 & $0.37^{*}$ & $-0.23^{*}$ & $0.21^{*}$ & $0.24^{*}$ & 1.00 & & & \\
\hline $\begin{array}{l}\text { (10) Recipient's retentive } \\
\text { capacity }\end{array}$ & 0.11 & $-0.21^{*}$ & 0.04 & -0.03 & $0.41^{*}$ & $-0.20^{*}$ & 0.11 & -0.02 & $0.61^{*}$ & 1.00 & & \\
\hline (11) Relationship & -0.05 & 0.18 & $0.16^{*}$ & -0.12 & $0.28^{*}$ & $-0.37^{*}$ & $0.40^{*}$ & $0.20^{*}$ & 0.14 & 0.14 & 1.00 & \\
\hline (12) Accuracy & -0.16 & $0.43^{*}$ & $0.40^{*}$ & -0.04 & $0.30^{*}$ & $-0.50^{*}$ & $0.30^{*}$ & $0.24^{*}$ & 0.15 & -0.01 & $0.32^{*}$ & 1.00 \\
\hline
\end{tabular}

*Significant at 0.05 level. All correlation coefficients are different than 1 at the 0.0012 level.

confidence interval of the observed correlations and testing whether this limit is smaller than the maximum possible correlation between the scales as computed with their reliability coefficients. Table 2 reports the correlations for all the variables. All construct pairs met the discriminant validity test at $p<0.0012$, lessening concerns over common method bias.

\section{Assumptions for the Analysis}

Predictors Are Invariant Throughout the Transfer. As a first approximation, predictors are assumed to remain invariant for the duration of the transfer. When such an assumption holds true, the timing of the measurement of the independent variables is not critical. This assumption is deemed reasonable because most of the predictors typically change slowly. However there may be exceptions. Some predictors such as the motivation of the source, the motivation of the recipient and the nature of the relationship between the units may be affected by the expected outcome of the transfer. Preexisting relationships between source and recipient subunits did exist for at least two years prior to the beginning of the transfer.

Cross-Sectional Comparison of Transfers Is Warranted. Leonard-Barton (1990) argues that it is necessary to measure multi-item constructs at a "defined point" in time if meaningful comparisons are wanted, because the meaning of complex constructs depends on when they are measured during a transfer. As point of reference for her study, she selected the "very first use of the technology in a routine production task" as the anchor point. She chose that point because it could be identified with a "satisfactory degree of precision." In this study, all questionnaires were completed within a narrow $^{12}$ band of 3.5 months, which started 5 months after the first day that knowledge was first put to use by the recipient. Thus, all transfers are at a defined and comparable point in time. Comparison across transfers is thus considered appropriate.

\section{Analysis}

We used hierarchical regression to test the hypotheses. Model 1 included only seven control variables pertaining to the main characteristics of the transfer plus cultural distance. Model 2 adds trustworthiness. Model 3 adds causal ambiguity and the interaction term. Finally, Model 4 adds the firm dummy variables. We report partial $F$ tests to significance of the added variables.

\section{Results}

The results for the regression analysis are reported in Table 3.

Model 1 is strongly significant $(F=7.466 ; p<0.001)$ with an adjusted $R$-square of 0.308 . In Model 2, the significance of the trustworthiness variable is shown both by its $t$-statistic and by the significance of the partial $F$ test. As well, the adjusted $R$-square increases to 0.344 .

The significance of the moderator is shown in Model 3 $(F=11.0070 ; p<0.0000)$ with the interaction term being significant at the 0.01 level. With the introduction of the interaction term, the adjusted $R$-square jumps to 0.504 . That the addition of the moderator is significant is confirmed by the results of the partial $F$ tests, which are significant at the 0.001 level. The addition of firm dummies in Model 4 detracts significantly from Model 3 as both the $F$-statistic and the adjusted $R$-square drop.

The control variables, when significant, are relatively stable and have the expected sign. A supportive context could be expected to contribute to accuracy. The source's motivation contributes to accuracy because it reflects the desire of the source to exchange knowledge, thus increasing the effective amount of opinion and explanatory information transferred to the recipient (Berger and Kellerman 1983). A recipient's absorptive capacity aids 
Table 3 Regressions of Transfer Effectiveness (Accuracy)

\begin{tabular}{|c|c|c|c|c|}
\hline & Model 1 & Model 2 & Model 3 & Model 4 \\
\hline \multicolumn{2}{|l|}{ Trustworthiness } & $0.231^{* *}$ & $(2.367)$ & $0.217^{*} \quad(2.205)$ \\
\hline \multicolumn{2}{|l|}{$\begin{array}{l}\text { Causal ambiguity } \\
\text { Interaction of causal ambiguity } \\
\text { and trustworthiness }\end{array}$} & & $\begin{array}{ll}-0.436^{* * *} & (-4.371) \\
-0.208^{* *} & (-2.550)\end{array}$ & $\begin{array}{l}-0.269^{* *}(-2.509) \\
-0.173^{*}(-1.976)\end{array}$ \\
\hline Source's motivation & $0.497^{* * *} \quad(4.165)$ & $0.435^{* * *}$ & $0.315^{* *}$ & $0.240^{*}$ \\
\hline Context & $0.254^{* *} \quad(2.768)$ & $0.251^{* *} \quad(2.512)$ & (1.863) & $0.162^{\wedge} \quad(1.772)$ \\
\hline Knowledge proveness & $-0.028 \quad(-0.302)$ & $-0.114 \quad(-1.177)$ & $-0.165^{\wedge} \quad(-1.895)$ & $-0.133(-1.414)$ \\
\hline Recipient's motivation & $-0.198^{\wedge} \quad(-1.713)$ & $(-1.555)$ & $(-1.806)$ & $-0.146 \quad(-1.416)$ \\
\hline Recipient's absorptive capacity & $0.174^{\wedge} \quad(1.677)$ & (1.139) & $(2.267)$ & $0.135 \quad(1.392)$ \\
\hline Recipient's retentive capacity & $-0.018 \quad(-0.171)$ & $(0.295)$ & $(-2.457)$ & $-0.184^{\wedge}(-1.807)$ \\
\hline Relationship & $0.150^{\wedge} \quad(1.706)$ & (1.852) & $(1.514)$ & $0.140 \quad(1.624)$ \\
\hline Cultural distance & $-0.041 \quad(-0.501)$ & $(-0.512)$ & $(0.031)$ & $-0.185 \quad(-1.470)$ \\
\hline \multicolumn{4}{|l|}{ Firm dummies } & Not significant \\
\hline$R$-square & 0.356 & 0.396 & 0.554 & 0.557 \\
\hline Adj. R-square & 0.308 & 0.344 & 0.504 & 0.479 \\
\hline$F$ & 7.466 & 7.637 & 11.070 & 7.103 \\
\hline Partial-F & & $\begin{array}{c}\text { Model } 1 \text { vs. } 2 \\
5.330^{*}\end{array}$ & $\begin{array}{c}\text { Model } 2 \text { vs. } 3 \\
6.994^{* * *}\end{array}$ & $\begin{array}{c}\text { Model } 3 \text { vs. } 4 \\
3.135^{* *}\end{array}$ \\
\hline Valid $N$ & 117 & 115 & 110 & 110 \\
\hline
\end{tabular}

Notes. $t$-values in parentheses.

*Significant at 0.05 level; **Significant at 0.01 level; ***Significant at 0.001 level; ^ Significant at 0.1 level.

the recipient in implementing new knowledge, while its retentive capacity hinders that implementation by creating barriers to unlearning old knowledge.

The coefficients of causal ambiguity and trustworthiness (Models 2-4) are highly significant and stable. Causal ambiguity $\left(\beta_{1}\right.$ in Equation (1.1)) is negatively related to accuracy (in Model 3: $-0.436 ; p<0.001$ ) and trustworthiness $\left(\beta_{2}\right.$ in Equation (1.1)) is positively related to accuracy (in Model 3: 0.213; $p<0.05$ ). The interaction effect $\left(\beta_{1 \times 2}\right.$ in Equation (1.1)) is negative and significant (in Model 3: $-0.208 ; p<0.01$ ), suggesting that the connection between trustworthiness and accuracy weakens as the moderator, causal ambiguity, increases.

To assess the net effect of perceptions of trustworthiness on accuracy, both the main effect and the interaction need to be considered. To complete the analysis of the total effect, we analyze its sign and magnitude, conditional on the level of the causal ambiguity, following procedures recommended by Aiken and West (1991). Table 4 reports the coefficients and $p$-values of trustworthiness, ${ }^{13}$ with causal ambiguity set to different values (using estimates from Model 3). When causal ambiguity is low ( -3 s.d.), a one standard deviation increase in perceived trustworthiness increases accuracy by 0.83 standard deviations. The effect is highly significant, confirming Hypothesis 1. Furthermore, supporting Hypothesis 2, as causal ambiguity increases, the total effect of trustworthiness on accuracy progressively weakens and then becomes negative and significant at two standard deviations above the mean, becoming highly significant at three standard deviations above the mean.

\section{Robustness of the Results}

Further analyses were conducted to explore the stability of the coefficients. Missing data were handled in three different ways. First, regressions were run with missing data deleted casewise, then with missing data deleted pairwise, and finally by substituting the missing value of the constructs with the mean value of the construct. Results remained stable.

To further test the robustness of the results and possible sensitivity to differences in the three perspectives sampled (source, recipient, and third party), we conducted an analysis where each perspective was treated as an individual observation, with potential differences

Table 4 Total Effect of the Perceived Trustworthiness on Accuracy

\begin{tabular}{lcc}
\hline Causal ambiguity set to: & $\begin{array}{c}\text { Total effect } \\
\beta_{\text {Trustworthiness tot }} \\
(t \text {-value })\end{array}$ \\
\hline Three standard deviations below the mean & $0.837^{* * *}$ & $(8.920)$ \\
Two standard deviations below the mean & $0.629^{* * *}$ & $(6.782)$ \\
One standard deviation below the mean & $0.421^{* * *}$ & $(4.651)$ \\
The mean & $0.213^{* *}$ & $(2.545)$ \\
One standard deviation above the mean & 0.005 & $(0.482)$ \\
Two standard deviations above the mean & $-0.203^{\wedge}$ & $(-1.525)$ \\
Three standard deviations above the mean & $-0.411^{* * *}(-3.463)$ \\
\hline
\end{tabular}

Notes. Values calculated using estimates of Model 3. ${ }^{* *}$ Significant at 0.01 level; ***Significant at 0.001 level; ^ Significant at 0.1 level.

The total effect of trustworthiness on accuracy is derived from the following equations that are based on the regression equation defined as Accuracy $=\beta_{0}+\beta_{1}$ Causal Ambiguity + $\beta_{2}$ Trustworthiness $+\beta_{1 \times 2}$ Causal Ambiguity $\times$ Trustworthiness $+\cdots+$ $\beta_{c n}$ Control Variable $:$ : 11.1] $\beta_{\text {Trustworthiness tot }}=\beta_{2}+\beta_{1 \times 2}$ Causal Ambiguity; [1.2] Accuracy $=\beta_{\text {Trustworthiness tot }} *$ Trustworthiness. 
controlled through the use of perspective dummy variables. Finally, we conducted an additional analysis where, rather than pool the perspectives or utilize each as an individual response for each transfer, we utilized only the best questionnaire in terms of completeness and level of detail in responses. The models remain highly significant with adj. $R$-square $\geq 0.420$ and all coefficients of the predictors remaining stable.

Finally, because some respondents were involved in more than one transfer, we conducted analyses to verify that a lack of independence between some observations did not significantly alter the results. First, we ran a series of regressions with all nonindependent observations removed. Second, we ran the analysis with one observation, chosen at random, from each nonindependent group included in the analysis and the remaining removed. In both cases the results remained stable and significant.

While the results remain stable to robustness checks, it is possible that the results are an artifact of reverse causality. While we predict that causal ambiguity acts as a moderator between perceptions of trustworthiness and accuracy, the perceptions of trustworthiness may also act as a mediator between causal ambiguity and accuracy. The presence of high causal ambiguity may lower perceptions of trustworthiness, with lower levels of the perception of trustworthiness directly contributing to lower levels of accuracy. This conception is in line with traditional theories of trust that predict that lower trust results in lower levels of social exchange (Carley 1991, Curall and Judge 1995, Tsai and Ghoshal 1998). To test this possibility, we conducted a mediation analysis. In Step 1 of the analysis the beta for causal ambiguity (with all control variables included) regressed on trustworthiness was -0.397 , significant at the 0.001 level. For Step 2, the beta for causal ambiguity regressed on accuracy (with trustworthiness left out but all control variables included) was -0.384 , significant at the 0.001 level. Finally, the beta for causal ambiguity regressed on accuracy with trustworthiness (and control variables) included in the model was -0.326 , significant at the 0.01 level. Thus, we find evidence of a small mediating effect but by no means a full mediating effect for perceptions of trustworthiness. As such, we can conclude that causal ambiguity has a significant moderating effect of its own. This removes some of the concern that the findings are due to an artifact rather than a real relationship.

\section{Discussion and Conclusion}

Our main finding is that the extent to which, on balance, the perceived trustworthiness of the source contributes to the effectiveness of intrafirm knowledge transfer depends on the nature of the knowledge transferred. Specifically, the accuracy of such transfers is moderated by the causal ambiguity of the knowledge. We focus on situations in which the transfer is primarily an effort to replicate, in another location, results that have been obtained through effective but nonetheless imperfectly understood practices.

This intricate effect of trustworthiness reflects the fact that trustworthiness promotes both functional and dysfunctional processes, fostering receptivity on the one hand and lessening the perceived need for vigilance on the other. When causal ambiguity is high, trustworthiness may prove counterproductive. Causal ambiguity drives a wedge between the perception and the reality of organizational practices, making additional validation essential. However, the degree of trustworthiness of the source may delay or inhibit efforts to validate and supplement the source's advice before the window of opportunity to implement change closes (Tyre and Orlikowski 1994). We show that as causal ambiguity increases, the effect of the perceived trustworthiness of the source on the accuracy of the transfer weakens progressively and then becomes negative.

It is important that the findings be interpreted with caution. First, the findings apply primarily to transfers of knowledge within firms. While it is possible that some of the same dynamics may exist in transfers between firms, the presumptive rationales for deriving perceptions of trustworthiness are likely to operate differently in an interfirm setting than within a firm, and the perceptions of trustworthiness are likely to be influenced by different processes of simplification and distortion. Furthermore, the study applies specifically to the context of transfers of organizational practices. Further research needs to study similar constructs in additional contexts to determine the extent of the phenomenon. Beyond questions of external validity, it should be noted that the correlational nature of this study precludes us from making strong assertions of causality. Finally, it should be noted that our measure of trustworthiness only includes the factor of ability and not benevolence and integrity. While this, along with controlling for source motivation, seems appropriate for studies of unit-level knowledge transfer, future research may want to explicitly include all three factors.

Despite the above limitations, the research contributes to the literature in a number of ways. It contributes to the literature of trust by examining perceptions of trustworthiness within a specific context: the transfer of practices within organizations. Rousseau et al. (1998) argue that context is critical to understanding trust, because trust may assume different, "multiplex" forms in different contexts. The moderating effect of causal ambiguity on the relationship between perceived trustworthiness and the accuracy of knowledge transfer could be interpreted as a change in the nature of trust that is contingent on the characteristics of the knowledge transferred. Indeed, the idea of multiplex forms of trust can be made more specific by noting that above a certain level of causal 
ambiguity (just over $1 \mathrm{s.d}$ ) the effect of trustworthiness could become negative. Thus, given high enough levels of causal ambiguity, trustworthiness could actually have a negative overall effect on the accuracy of knowledge transfer.

It is worthwhile to return to our theorizing to speculate on why that may be the case as the overall effect becomes negative and significant. Indeed, when causal ambiguity results in a simplified conception of the Arrow core, one would expect a progressive weakening of the relationship between perceived trustworthiness and accuracy with increasing levels of causal ambiguity. Postponing direct observation under these conditions results in a somewhat simplified replica, thus dampening the link between trustworthiness and accuracy. However, postponing direct observation when the conception of the Arrow core offered by the source is not merely simplified, but actually distorted may result not in a partial, but rather in an inaccurate copy of the template. This provides a plausible explanation for a negative relationship between perceived trustworthiness and accuracy.

These implications could be generalized by noting that in the knowledge-transfer domain, trustworthiness is closely linked with trust, and causal ambiguity stands for a fundamental attribute of organizational practices. Thus, we can derive the broader implication that the effect of trust in organizational learning is moderated by the characteristics of the knowledge transferred.

This broader implication could provide an entry point for a research agenda on the so-called "dark" side of trust. Indeed, it is generally believed that trustworthiness becomes increasingly relevant to social conduct in contexts with ambiguous elements (Belliveau et al. 1996, Chaiken 1980, Petty and Cacioppo 1996, Podolny 1993). Trusting behavior in such situations is likely to reflect depersonalized presumptive rationales based on lessons from prior history, information provided by third parties, affiliation with specific social categories, formal roles, and organizational rules regarding transaction norms (Kramer 1999). In such situations, however, miscalculation is possible and trust could be misplaced. Though helpful in some circumstances, trust could be dysfunctional in others. The characteristics of the knowledge, e.g., causal ambiguity, could provide discriminating factors between these two classes of circumstances, defining transitional thresholds between different types of trust. The implications for practice seem clear. When causal ambiguity is likely to be high, imputations of trustworthiness (especially in terms of ability) should be made with great care.

The difficulty is in making an appropriate valuation of trustworthiness. Even with abundant information, trustworthiness at the unit level could be hard to establish. This can be seen in the example of IBM Rochester, a flagship manufacturing plant at IBM, which produced the AS/400 computer system. IBM's Rochester plant had the highest morale, lowest turnover and absenteeism rates in IBM, won Minnesota's Safety Award for 10 consecutive years, and IBM's U.S. Market Driven Quality Award for two consecutive years. Yet, it was not until it won the Malcolm Baldridge National Quality Award, a highly coveted designation conferred by the President of the United States, that other units within IBM considered the Rochester plant to be a viable benchmark. It took a very strong signal from a third party, indeed the strongest possible signal at the time, to transform the perception of trustworthiness (in terms of ability) and therefore of the relevance of the fruits of Rochester's experiential learning for other organizational subunits. In ambiguous situations, a third party, however sophisticated and savvy, may fall prey to the dark side of trust by inferring that a source could properly signal the limits of its trustworthiness. Such a third party may have the organizational visibility and authority to certify sources as trustworthy, even though these sources may be uncertain about the extent of their own ability, because of causal ambiguity. Such circumstance is a vivid example of how misplaced trust could foster superstitious learning (Levitt and March 1988).

The results of this study illustrate some elements of the "true functioning" of trust in the context of knowledge transfer, highlighting how causal ambiguity moderates the role of perceived trustworthiness in the process of transfer. Perceived trustworthiness has a more nuanced and potentially intricate effect on the effectiveness of the transfer. Awareness of the level of irreducible uncertainty may help prevent the accumulation of superstitious learning and thus increase the effectiveness of the application of the lessons of experience in different contexts. We do hope that our study suggests how knowledge transfer could serve as a useful context to advance our understanding of the "true functioning" of trust.

\section{Acknowledgments}

The authors acknowledge helpful comments from M. Scott Poole, Aks Zaheer, Sumantra Ghoshal (r.s.p.), Witold Henizs, Paul Ingram, Linda Argote, Dan Levinthal, Bill McEvily, Marshall Meyer, Peter Moran, Vincenzo Perrone, Quy Huy, John Stopford, Sidney Winter, JoAnne Yates, Rod Kramer, Lynn Zucker, Diego Gambetta, participants of seminars at Duke, Wharton, London Business School, and MIT, and a senior editor and three anonymous reviewers of Organization Science. Financial support was graciously provided by the Reginald Jones Center and by the Hunstman Center at The Wharton School of the University of Pennsylvania. Errors and omissions are solely the authors' responsibility.

\section{Appendix 1. Identification and Selection of the Companies for the Sample}

Two heuristics were used to identify firms that share best practices internally. One heuristic was to seek large best-inclass firms that have small MES (Minimum Efficient Scale). These firms have many similar operating units that could 
readily benefit from sharing best practices and thus have strong incentives to replicate those best practices. The other heuristic was to approach firms that are active in competitive benchmarking. An emerging norm in benchmarking is to benchmark inside the firm before attempting to benchmark outside the firm, with internal benchmarking often leading to transfers of identified internal best practices. Contact with benchmarking firms was sought through the International Benchmarking Clearinghouse of the American Productivity and Quality Center and through the Council on Benchmarking of the Strategic Planning Institute (cf. Main 1992). After careful scrutiny, this institution endorsed the survey and brought it to the attention of its members. More than 2,000 copies of a one-page description of the survey were mailed to the IBC membership - around 200 companies at that time. Additional firms with multiple small-scale operations were contacted individually. Besides relying on those two heuristics (small MES and active in competitive benchmarking) some firms were contacted directly based on their earned reputation as pioneers in the transfer of best practices inside the firm.

The first step of the survey was devised as a feasibility test. This test required companies to generate a list of transfers to study and a list of parties involved in those transfers (i.e., of respondents). To pass the feasibility test, companies had to submit a written statement of commitment to the project signed by a senior executive. This executive was requested to nominate a visible coordinator for the survey. The coordinator would scrutinize the pilot questionnaire, coordinate the administration of the final questionnaire, and act as a liaison with the researcher regarding any other aspect of the project. The first task for the nominated coordinators was to provide a list, and a succinct description, of the practices that their company wished to study. They were also requested to provide a list of actual transfers of those practices. For each transfer in that list, coordinators were requested to identify a representative of the source unit, a representative of the recipient unit, and a representative of a third party.

To select "practices" for this study, the coordinators were directed to search for transfers between peer units of important activities or processes and to prefer those that showed evidence of difficulty during the transfer. They were also instructed to rule out practices that could be performed by a single individual and to exclusively favor those practices that required the coordinated effort of several individuals.

\section{Appendix 2. Operationalization of the Control Variables}

- Each sentence in the description of the scales below is the full text of the question as it appears in the questionnaire.

- Unless otherwise indicated, answers were scored using the default scale ( $\mathrm{Y}$ ! Y o N N!).

- The key for the default scale is $\mathrm{Y} !=$ "Yes!"; $\mathrm{Y}=$ "yes, but"; o = "no opinion"; $\mathrm{N}=$ "no, not really"; N! = "No!".

- The overall score for each scale was computed by adding the standardized scores obtained from each question.

Source Motivation ( $\alpha=0.93$; items $=13$ ) binary scales; positive relationship to accuracy predicted

Source saw benefit in: measuring its own performance; understanding its own practices; sharing this understanding with other units; sharing the limits of this understanding with other units; assessing the feasibility of the transfer; communicating with [recipient]; planning the transfer; documenting [practice] for transfer; implementing [recipient's] support systems; training [recipient's] personnel; helping [recipient] troubleshoot; helping resolve recipient's unexpected problems; lending skilled personnel.

Recipient Motivation $(\alpha=0.93$; items $=14)$ binary items; positive relationship to accuracy predicted

Recipient saw benefit in: measuring its own performance; comparing it with the performance of other units; understanding its own practices; absorbing [source's] understanding; analyzing the feasibility of adopting [practice]; communicating its needs to [source]; planning the transfer; implementing the systems and facilities for [practice]; assigning personnel full time to the transfer; assigning personnel to be trained in [practice]; understanding the implications of the transfer; troubleshooting [practice]; insuring that its people knew their jobs; insuring that its people consented to keep doing their jobs.

Recipient Absorptive Capacity ( $\alpha=0.83$; items $=9$ ) default scale; positive relationship to accuracy predicted

Members of [recipient] have a common language to deal with the [practice]; [recipient] had a vision of what it was trying to achieve through the transfer; [recipient] had information on the state of the art of the [practice]; [recipient] had a clear division of roles and responsibilities to implement the [practice]; [recipient] had the necessary skills to implement the [practice]; [recipient] had the technical competence to absorb the [practice]; [recipient] had the managerial competence to absorb the [practice]; it is well known who can best exploit new information about the [practice] within [recipient]; it is well known who can help solve problems associated with the [practice].

Recipient Retentive Ability ( $\alpha=0.81$; items $=6)$ default scale; negative relationship to accuracy predicted

[recipient] periodically retrains existing personnel on the [practice]; [recipient] has mechanisms to detect malfunctions of the [practice]; [recipient] regularly measures performance and corrects problems as soon as they happen; [recipient's] personnel can predict how they will be rewarded for good performance in the [practice]; [recipient's] personnel are provided with numerous opportunities to commit freely and publicly to perform their role; at [recipient] there is a clear focal point for the [practice].

Proveness of Knowledge ( $\alpha=0.67$; items $=3$ ) default scale unless indicated; positive relationship to accuracy predicted We had solid proof that [practice] was really helpful; [practice] contributes significantly to the competitive advantage of [company]; for the success of [company], the [practice] is: 1. CRITICAL, 2. VERY IMPORTANT, 3. FAIRLY IMPORTANT, 4. FAIRLY UNIMPORTANT, Or 5. NOT IMPORTANT AT ALL.

Relationship Between Source and Recipient $(\alpha=0.71$; items $=3$ ) default scale; positive relationship to accuracy predicted

Communication between [source] and [recipient] is 1. VERY EASY, 2. FAIRLY EASY, 3. FAIRLY DEMANDING, or 4. VERY DEMANDING; collaboration between [source] and [recipient] 1. IS SOUGHT ACTIVELY, 2. IS WELL RECEIVED, 3. PREFERABLY AVOIDED, and 4. ONLY IF NO OTHER CHOICE; collaboration between [source] and [recipient] (same scale as previous question). 
Organizational Context $(\alpha=0.77$; items $=14)$ default scale; positive relationship to accuracy predicted

Existing performance measures of the [practice] are detailed enough to be meaningful; performance measures of the [practice] are taken frequently enough to be timely; performance measures of the [practice] from different units are easily comparable; [company] enforces companywide standard policies with respect to the [practice]; at [company] there is constant pressure to improve performance; it is easy to justify time spent visiting other units; to visit another unit, it is easy to justify travel expenses; at [company] improving performance by copying and adapting practices from other units is as legitimate as improving performance from own creativity; at [company] a unit that exposes those needs that it is unable to meet on its own loses status (RS); at [company], a unit that exposes unresolved problems loses status (RS); at [company], despite structural differences, units can always learn from one another; normally a best-in-class practice is most likely to be found outside [company] (RS); at [company] managers seem to prefer to use external sources of help and support even though they are more expensive and less useful (RS); at [company], corporate pride and values encourage managers not to look outside for help or to share with the outside (RS).

\section{Endnotes}

${ }^{1}$ Mayer et al. (1995, p. 716) define trustworthiness in terms of a trustee's "expectations of how another person will behave, based on that person's current and previous implicit and explicit claims."

${ }^{2}$ Allen and Stiff's (1989) notion of "credibility" is equivalent to the Mayer et al. (1995) construct of trustworthiness.

${ }^{3}$ Consistent results are seen as the product of organizational practices and routines (Nelson and Winter 1982). Routines consist of connected, recurrent behaviors coordinating the actions of multiple individuals to produce a consistent output. Knowledge transfer, in this sense, is the replication of routines across geographical space.

${ }^{4} \mathrm{~A}$ recipient (and source) is defined as an organizational unit. Following Nelson and Winter (1982, p. 98) the expression "organizational unit" is thought of as any entity that can "accomplish something on its own." As they explain, organizational unit is used mostly to mean an individual, however, "it is sometimes convenient to think of an organizational subunit as a 'member' of the larger organization." Trust, under this specification and particularly in intraorganizational transfers, is conceived as an interunit, rather than interorganizational, phenomenon.

${ }^{5}$ This statement draws on Attewell's (1992) notion of economizing on learning.

${ }^{6}$ In particular, McAllister (1995) argues that a high level of cognition-based trust, which is the trust derived from the evaluation of the positive characteristics of the other person, is associated with little control-based monitoring, which is the monitoring of the other person's actions to control her or him. ${ }^{7}$ Except in those situations where the source precisely signals the limits of its advice.

${ }^{8}$ The sample contained both technical and administrative practices. Examples of technical practices are software development procedures and drawing standards. Examples of administrative practices are upward appraisal and activitybased costing (ABC). Full disclosure of the practices studied is precluded by a guarantee of confidentiality.
${ }^{9}$ In total, 184 transfers of 44 practices were identified, requiring 445 questionnaires (in many cases it was not possible to identify a third party to the transfer). Response rate was calculated as 271/445. The coordinators from each company provided a detailed account for each questionnaire sent, thus providing an exhaustive nonresponse follow up. The most common justification for nonresponse was the lack of detailed familiarity with the transfer. Other reasons for nonresponse were "refused" or "left the company."

${ }^{10}$ Ability is defined as "that group of skills, competencies, and characteristics that enable a party to have influence within a specific domain" (Mayer et al. 1995, p. 717).

${ }^{11}$ This distinction is similar to the one made by Henderson and Clark (1990) between architectural knowledge and component knowledge.

${ }^{12}$ Such a band of 3.5 months can be considered narrow, because it means that all transfers were sampled early on in the integration stage that has been documented to last between 1.5 to 2 years.

${ }^{13} P$-value for the total effect is calculated using the following $t$-statistic: $t$ Trustworthiness tot $=\beta$ Trustworthiness tot/SE( $\beta$ Trustworthiness tot), where SE( $\beta$ Trustworthiness tot $)=\sqrt{ }[\operatorname{VAR}(\beta 2)+$ Causal Ambiguity $2 \operatorname{VAR}(\beta 1 \times 2)+$ 2Causal Ambiguity $\operatorname{COV}(\beta 2, \beta 1 \times 2)]$.

\section{References}

Aiken, L. S., S. G. West. 1991. Multiple Regression: Testing and Interpreting Interactions. Sage Publications, Newbury Park, CA.

Allen, M., J. Stiff. 1989. Testing three models for the sleeper effect. Western J. Speech Comm. 53 411-426.

Andrews, K. M., B. L. Delahaye. 2000. Influences on knowledge processes in organizational learning: The psychosocial filter. J. Management Stud. 37(6) 797-810.

Argote, L. 1999. Organizational Learning: Creating, Retaining, and Transferring Knowledge. Kluwer Academic, Boston, MA.

Argyris, C., D. A. Schon. 1978. Organizational Learning. Addison Wesley, Reading, MA.

Armor, D. J. 1974. Theta reliability and factor scaling. H. L. Costner, ed. Sociological Methodology 1973-1974. Jossey-Bass, San Francisco, CA, 17-50.

Attewell, P. 1992. Technology diffusion and organizational learning: The case of business computing. Organ. Sci. 3(1) 1-19.

Barber, B. 1983. The Logic and Limits of Trust. Rutgers University Press, New Brunswick, NJ.

Bartlett, C. A., S. Ghoshal. 1989. Managing Across Borders: The Transnational Solution. Harvard Business School Press, Boston, MA.

Baum, J. A. C., P. Ingram. 1998. Survival-enhancing learning in the Manhattan hotel industry, 1898-1980. Management Sci. 44(7) 996-1016.

Belliveau, M., C. O’Reilly, J. Wade. 1996. Social capital at the top: Effects of social similarity and status on CEO compensation. Acad. Management J. 39(6) 1568-1593.

Berger, C., K. Kellerman. 1983. To ask or not to ask: Is that a question? R. Bostrom, ed. Communication Yearbook 7. Sage, Newbury Park, CA, 342-368.

Bohn, R. E. 1994. Measuring and managing technological knowledge. Sloan Management Rev. 36(1) 61-73. 
Boisot, M. 1995. Information Space: A Framework for Learning in Organizations Institutions, and Culture. Routledge, London, U.K.

Brooks, F. P. 1995. The Mythical Man-Month: Essays on Software Engineering. Addison-Wesley, Reading, MA.

Brown, J. S., P. Duguid. 1991. Organizational learning and communities-of-practice: Toward a unified view of working, learning, and innovation. Organ. Sci. 2(1) 40-57.

Carley, K. 1991. A theory of group stability. Amer. Sociological Rev. 56(3) 331-354.

Carmines, E. G., R. A. Zeller. 1979. Reliability and Validity Assessment. Sage, Beverly Hills, CA.

Carroll, J. S. 1998. Organizational learning activities in high-hazard industries: The logics underlying self-analysis. The J. Management Stud. 35(6) 699-717.

Chaiken, S. 1980. Heuristic versus systematic information procesing and the use of source versus message cues in persuasion. $J$. Personality Soc. Psych. 39 752-766.

Curall, S., T. Judge. 1995. Measuring trust between organizational boundary role persons. Organ. Behavior Human Decision Processes 64 151-170.

Dirks, K. T., D. L. Ferrin. 2001. The role of trust in organizational settings. Organ. Sci. 12(4) 450-467.

Eisenberg, E., S. Phillips. 1991. Miscommunication in organizations. N. Coupland, H. Giles, J. Wiermann, eds. "Miscommunication" and Problematic Talk. Sage, Newbury Park, CA, 244-258.

Financial Times. 1997. Xerox makes copies. Financial Times.

Gerbing, D. W., J. C. Anderson. 1988. An updated paradigm for scale development incorporating unidimensionality and its assessment. J. Marketing Res. XXV(May) 186-192.

Golden, B. R. 1992. The past is the past-Or is it? The use of retrospective accounts as indicators of past strategy. Acad. Management J. 35(4) 848-860.

Great Harvest Bread Co. 1999. Apprenticeship Agreement 2. Great Harvest Bread Co.

Haleblian, J., S. Finkelstein. 1999. The influence of organizational acquisition experience on acquisition performance: A behavioral perspective. Admin. Sci. Quart. 44(1) 29-56.

Henderson, R. M., K. B. Clark. 1990. Architectural innovation: The reconfiguration of existing product technologies and the failure of established firms. Admin. Sci. Quart. 35(1) 9-30.

Hovland, C., A. Lumsdaine, F. Sheffield. 1949. Experiments in Mass Communication. Princeton University Press, Princeton, NJ.

Iansiti, M. 1998. Technology Integration: Making Critical Choices in a Dynamic World. Harvard Business School Press, Boston, MA.

King A. W., C. P. Zeithaml. 2001. Competencies and firm performance: Examining the causal ambiguity paradox. Strategic Management J. 22(1) 75-99.

Kogut, B., U. Zander. 1992. Knowledge of the firm, combinative capabilities and the replication of technology. Organ. Sci. 3(3) 383-397.

Kostova, T., K. Roth. 2002. Adoption of an organizational practice by subsidiaries of multinational corporations: Institutional and relational effects. Acad. Management J. 45(1) 215-233.

Kramer, R. M. 1999. Trust and distrust in organizations: Emerging perspectives, enduring questions. Annual Rev. Psych. 50 569-598.
Langfred, Claus W. 2004. Too much of a good thing? Negative effects of high trust and individual autonomy on self-managing teams. Acad. Management J. 47(3) 385-399.

Leonard-Barton, D. 1990. A dual methodology for case studies: Synergistic use of a longitudinal single site with replicated multiple sites. Organ. Sci. 1(3) 248-266.

Levitt, B., J. G. March. 1988. Organizational learning. Annual Rev. Sociology 14 319-340.

Lewicki, R. J., D. J. McAllister, R. J. Bies. 1998. Trust and distrust: New relationships and realities. Acad. Management Rev. 23(3) $438-458$.

Lewis, J., A. Weigert. 1985. Trust as a social reality. Soc. Forces 63 967-985.

Lippman, S. A., R. P. Rumelt. 1982. Uncertain imitability: An analysis of interfirm differences in efficiency under competition. Bell $J$. Econom. 13 418-438.

Main, J. 1992. How to steal the best ideas around. Fortune (October 19) $86-89$

March, J. G., L. S. Sproull, M. Tamuz. 1991. Learning from samples of one or fewer. Organ. Sci. 2(1) 1-13.

Mayer, R. C., J. Davis, F. Schoorman. 1995. An integration model of organizational trust. The Acad. Management Rev. 20(3) 709-734.

McAllister, D. 1995. Affect- and cognition-based trust as foundation for interpersonal cooperation in organizations. Acad. Management J. 38(1) 24-60.

McEvily, B., V. Perrone, A. Zaheer. 2003. Trust as an organizing principle. Organ. Sci. 14(1) 91-103.

Meyer, J., B. Rowan. 1977. Institutionalized organizations: Formal structure as myth and ceremony. Amer. J. Sociology 83 340-361.

Miller, D. 1993. The architecture of simplicity. Acad. Management Rev. 18(1) 116-138.

Muchinsky, P. 1977. An intraorganizational analysis of the Roberts and O'Reilly organizational communication questionnaire. J. Appl. Psych. 62 184-188.

Nelson, R., S. Winter. 1982. An Evolutionary Theory of Economic Change. Belknap Press, Cambridge, MA

Noteboom, N., H. Berger, N. Noorderhaven. 1997. Effects of trust and governance on relational risk. Acad. Management J. 40(2) 308-338.

Nunnally, J. C. 1978. Psychometric Theory. McGraw-Hill, New York.

O’Dell, C. S., C. J. Grayson, N. Essaides. 1998. If Only We Knew What We Know: The Transfer of Internal Knowledge and Best Practice. Free Press, New York.

Perry, D. K. 1996. Theory and Research in Mass Communication: Contexts and Consequences. L. Erlbaum Associates, Mahwah, $\mathrm{NJ}$

Petty, R. E., J. T. Cacioppo. 1996. Attitudes and Persuasion: Classic and Contemporary Approaches. Westview Press, Boulder, CO.

Podolny, J. 1993. A status-based model of market competition. Amer. J. Sociology 98(4) 829-872.

Polanyi, M. 1962. Personal Knowledge: Towards a Post-Critical Philosophy. Chicago University Press, Chicago, IL.

Prahalad, C. K., Y. L. Doz. 1987. The Multinational Mission: Balancing Local Demands and Global Vision. Free Press, New York.

Roberts, K., C. O’Reilly. 1974. Measuring organizational communication. J. Appl. Psych. 59 321-326. 
Rousseau, D. M., S. B. Sitkin, R. S. Burt, C. Camerer. 1998. Not so different after all: A cross-discipline view of trust. Acad. Management Rev. 23(3) 393-404.

Shannon, C. E., W. Weaver. 1949. The Mathematical Theory of Communication. University of Illinois Press, Chicago, IL.

Sitkin, S. B., N. L. Roth. 1993. Explaining the limited effectiveness of legalistic "remedies" for trust/distrust. Organ. Sci. 4 367-392.

Stohl, C., C. Redding. 1987. Messages and message exchange process. F. Jablin, L. Putnam, K. Roberts, L. Porter, eds. Handbook of Organizational Communication: An Interdisciplinary Perspective. Sage, Beverly Hills, CA, 451-502.

Tsai, W., S. Ghoshal. 1998. Social capital and value creation: The role of intrafirm networks. Acad. Management J. 41(4) 464-476.

Tyler, T. R., P. Degoey. 1996. Trust in organizational authorities: The influence of motive attributions in willingness to accept decisions. R. M. Kramer, T. R. Tyler, eds. Trust in Organizations: Frontiers of Theory and Research. Sage, Thousand Oaks, CA.

Tyre, M. J., W. J. Orlikowski. 1994. Windows of opportunity: Temporal patterns of technological adaptation in organization. Organ. Sci. 5(1) 98-118.

Uzzi, B. 1997. Social structure and competition in interfirm networks: The paradox of embeddedness. Admin. Sci. Quart. 42 35-67.
Walton, R. E. 1975. The diffusion of new work structures: Explaining why success didn't take. Organ. Dynamics 3(Winter) 3-21.

Webb, G. 1996. Trust and crises. R. M. Kramer, T. R. Tyler, eds. Trust in Organizations: Frontiers of Theory and Research. Sage, Thousand Oaks, CA.

Williamson, O. E. 1975. Markets and Hierarchies: Analysis and Antitrust Implications. Free Press, New York.

Winter, S. G. 1987. Knowledge and competence as strategic assets. D. Teece, ed. The Competitive Challenge-Strategies for Industrial Innovation and Renewal. Ballinger, Cambridge, MA, 159-184.

Winter, S. G., G. Szulanski. 2001. Replication as strategy. Organ. Sci. 12(6) 730-743.

Zaheer, A., B. McEvily, V. Perrone. 1998. Does trust matter? Exploring the effects of interorganizational and interpersonal trust on performance. Organ. Sci. 9(2) 141-159.

Zander, U., B. Kogut. 1995. Knowledge and the speed of the transfer and imitation of organizational capabilities: An empirical test. Organ. Sci. 6(1) 76-92.

Zeller, R. A., E. G. Carmines. 1980. Measurement in the Social Sciences: The Link Between Theory and Data. Cambridge University Press, Cambridge, U.K. 